\title{
Química de gènere des de la didàctica de les ciències socials
}

\author{
Una visió sobre la igualtat de gèneres
}

\section{a través de la història de la química i un recurs per desenvolupar}

\author{
Enric Ramiro Roca \\ Universitat Jaume I \\ enricramiroroca@gmail.com
}

Resum: En primer lloc, hem traçat el marc genèric de la desigualtat de gènere fent un recorregut pels sectors socials, religiosos $i$ acadèmics que ens mostren l'estat de la qüestió.

A continuació, fem una proposta concreta d'un recurs didàctic que ajude a la visibilitat de la dona en el camp cientific. Per a això, hem triat un document que combina diferents tipologies lingüístiques (biogràfica, descriptiva $i$ instructiva), amb les matemàtiques, l'art del dibuix, el disseny i la poesia, diferents llenguatges com l'escrit, el visual i l'iconogràfic, la pedagogia i les ciències socials, molt en particular la història.

Paraules clau: igualtat de gèneres, País Valencià, matemàgia, recurs didàctic.

Abstract: First, we have traced the generic framework going through the social, religious and academic sectors to show the state of this issue.

We end with a concrete proposal for an educational resource to help the visibility of women and gender equality. In order to do this, we have chosen a document that combines different text typologies (biographical, descriptive and instructive), together with mathematics, the art of drawing, design and poetry, different types of language such as written, visual and iconographic, pedagogy and social sciences, especially history.

Keywords: gender equality, Valencian Country, Maths Magic, teaching resources.

\section{Introducció}

Per poc que aguaitem als mitjans de comunicació, podrem comprovar fàcilment la presència de notícies on la dona és la protagonista. En uns casos es fa constar la seua discriminació en el món actual, fins i tot en països occidentals, i en altres és novetat el seu progrés cap a la igualtat amb el gènere masculí, la qual cosa demostra evidentment que no ho ha aconseguit (vegeu figura 1). En tot cas, durant les últimes dècades sembla que es constata un progrés cap a l'equilibri, però amb senyals d'incontinència com algunes actituds dels adolescents, les notícies sobre violència de gènere, la redacció de lleis com la de restricció de l'avortament, la proliferació d'acudits masclistes o altres. Però on resideix majorment el perill és en les formes subliminals que tenen algunes societats tècnicament avançades per dissenyar marcs d'igualtat que, sense les necessàries compensacions reals, arrosseguen una discriminació oculta. En definitiva, moltes accions queden en el marc però sense quadre, com ocorre de forma similar en altres aspectes de la nostra societat com el miratge de la normalització lingüística de les llengües minoritzades. ${ }^{1}$

1 En aquest sentit, la situació és semblant als problemes que tenen les llengües minoritzades com el català al País Valencià. Sovint apareix la llengua pròpia únicament en els títols de les jornades, cursos o revistes, per intentar donar una imatge que no és real. 
Figura 1. Violència masclista entre adolescents.

\begin{tabular}{l} 
La violencia \\
machista entre \\
adolescentes Se \\
dispara un $30 \%$ \\
"Creí que era solo cosa \\
de casadas, adultas" \\
\hline MARÍA R. SAHUQUILIO, Madrid \\
\hline Las causas judiciales por violen- \\
cia machista entre adolescentes \\
pasaron de 473 a 632 entre 2011 y \\
2012. "Creí que solo pasaba con \\
mujeres casadas, adultas", cuen- \\
ta Cristina, que sufrió esa violen- \\
cia con 15 años. PÁGinas 38 r 39
\end{tabular}

Font: Levante, 30.10.2013.

En l'estudi que ens ocupa, hem optat per la denominació de geografia del gènere, enfront d'altres com geografia de les dones o geografia feminista, i adoptem la definició de la professora Ana Sabaté, que fa a ella com "aquella que incorpora les aportacions teòriques del feminisme a l'explicació i interpretació dels fets" (Sabaté, Rodríguez i Díaz, 1995: 16). Entenem per cultura de gènere el conjunt d'elements que ens serveixen per interpretar la distinció masculí-femení en l'àmbit del que significa ser home-dona, i com a característica de la identitat i de les actituds personals (Crawford, 2006).

En l'àmbit docent, pretenem contribuir a desenvolupar les competències per a la igualtat (Elboj, Flecha i Iñiguez, 2009: 111):

- Conèixer les jerarquies de poder i reflexionar sobre com les interioritzem a través dels processos de socialització.

- Desenvolupar l'esperit crític respecte al patriarcat $\mathrm{i}$ als diferents fonamentalismes basats en les relacions de poder.

- Desenvolupar les relacions afectives no fonamentades en el poder, sinó en la igualtat.

Aquestes competències encara són un repte en l'educació actual, i no per una oposició a la seua redacció o desenvolupament, sinó per un règim de gènere que continua privilegiant el masculí davant el femení en un sistema patriarcal que ha estat objecte de "neutralització". Està tan "assumida" la igualtat en la nostra societat que es fan invisibles les seues desigualtats, i únicament de forma esporàdica es fan manifestes les diferències. Per això, és cada vegada més necessària una acció social, i no tan sols escolar, que contribuïsca a l'equilibri necessari de gèneres des de la realitat, la justícia i no des de la imatge.

Com a recurs didàctic, hem introduït un exemple de posada en pràctica d'un material que pot ajudar des de la didàctica de les ciències socials a aquesta connexió entre tots els sectors socials, amb independència del nivell acadèmic, les creences o ideologies, d'una forma interdisciplinària i que pot ser utilitzada des de primària fins a la universitat.

\section{L'estat de la qüestió}

Tant a l'Estat espanyol com al nostre país, les dones són més i hi ha més casades, més vídues i més divorciades. En la vida quotidiana, dediquen més del doble que els seus companys al treball domèstic, menys a l'oci i, encara que condueixen menys, tenen proporcionalment molts menys accidents que els homes. En educació hi ha més analfabetes, les que estudien es concentren en el primer cicle universitari i en les carreres de ciències de la salut, humanitats i ciències socials i jurídiques, i molt poques en les carreres tècniques. Però és a les institucions de "poder" $\mathrm{i}$ militars on la seua presència és anecdòtica: mínima a les forces armades, la Guàrdia Civil, Policia Nacional i municipal o en comissaries.

En el camp judicial, la proporció augmenta en relació inversa a la categoria, una correspondència semblant a la política, on hi ha presència al govern, però molt poca en les altes capes de l'Administració. En la militància sindical no arriben al 25\% de l'afiliació dels grans sindicats i al parlament europeu el superen molt tímidament. En salut, moren menys que els homes a qualsevol edat, es fan menys trasplantaments i quan s'hospitalitzen hi estan menys dies. ${ }^{2}$

Un altre sector molt influent és el relacionat amb l'àmbit religiós en general, i molt especial-

2 El País, 08.03.1998: 14-15. 
ment el del món catòlic. Són nombroses les declaracions de destacats representants d'aquesta jerarquia eclesial que no han estat desqualificats pel Vaticà, encara que han estat criticats per diferents associacions teològiques i moviments de base cristians que han deixat constància de la seua peculiar visió sobre la igualtat de gènere. I així ens hi podríem allargar, però no és el cas, ja que pensem que està prou descrit el grau d'igualtat de gènere que emana actualment de la nostra societat occidental i desenvolupada.

No dubtem que en alguns casos s'avança i, en la majoria de les situacions, la tendència és a l'equilibri. No obstant això, aquesta evolució és molt més lenta del que sembla i en alguns casos amb retrocessos o costa que la dona assumisca dos rols amb un esforç molt superior al del seu company. De fet, sovint es presenten les oportunitats laborals sense cap discriminació frontal, però sí de forma subliminal. És el cas de la maternitat, que, almenys fins al naixement, recau fonamentalment sobre la dona i per a la qual caldria dissenyar mesures de compensació positiva. En altres casos, són la realització de viatges, la superació de proves físiques o algunes tradicions les que entorpeixen considerablement l'equilibri entre sexes.

Figura 2. Imatge d'una classe del Grau de Mestre d'Infantil. El nombre de dones universitàries no es correspon amb l'accés als llocs de decisió.

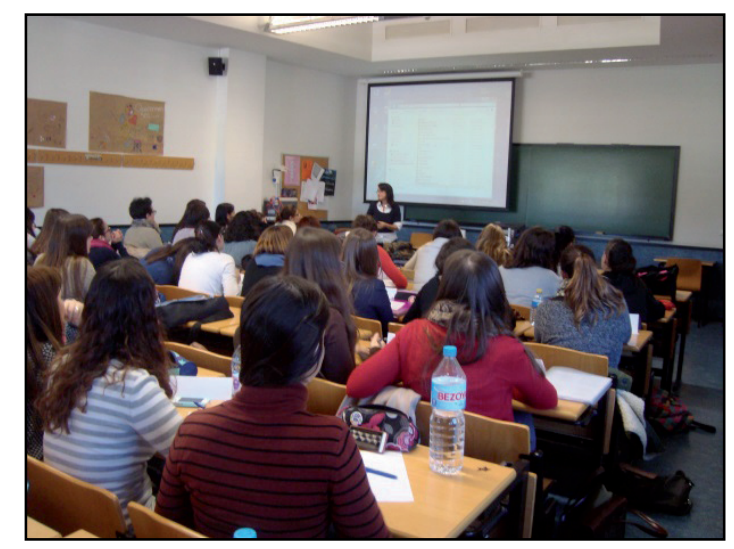

Font: elaboració pròpia.

Ara bé, què passa en el món de la cultura? Què passa en el món educatiu? És més progres- sista aquest camp que la societat? En tot el sistema educatiu, prop del $57 \%$ del professorat són dones, distribuïdes de forma molt desigual en els diferents nivells.

Així, en educació infantil, tenen una presència d'un $96 \%$, enfront del $4 \%$ masculí, mentre que a primària el percentatge se situa en el $64 \% \mathrm{i}$ a secundària i batxillerat la distribució s'equilibra al voltant del $50 \%$ de cada sexe. ${ }^{3}$

A la universitat espanyola, segons informen les professores García de Cortázar i García de León, en un recent informe del Centre d'Investigacions Sociològiques, tot i que la universitat apareix com el paradigma de la igualtat on teòricament no hi ha prejudicis, alguna cosa no funciona, i es reprodueix l'esquema masculí que persisteix a la nostra societat (García de Cortázar i García de León, 1997). A més, el ritme d'incorporació de les dones a llocs universitaris de responsabilitat és molt més lent que el seu ingrés i èxit en els estudis. Igualment, la distribució per carreres universitàries és considerablement desproporcionada per sexes, amb una concentració femenina a humanitats $i$ ciències socials, mentre que a les de ciències pures i enginyeries la seua proporció és molt baixa.

\section{La màgia del joc, la nostra aliada}

Hi ha moltes formes de divulgar una idea, un valor, uns coneixements, i possiblement totes són positives en consideració al seu context, el seu públic i el seu temps. No obstant això, i des de l'experiència pròpia, considerem que la millor manera d'influir en els altres és creant connexions favorables amb el nostre interlocutor. Si no es construeixen aquests llaços, difícilment podrem deixar empremta de la nostra informació, i en aquest sentit el joc representa un bon aliat.

La proposta que presentem va ser realitzada per encàrrec del CSIC per celebrar l'Any Internacional de la Química, però es pot adaptar a qualsevol circumstància. L'objectiu principal era mostrar la imatge d'igualtat de gènere sobre la base de representar el mateix nombre de dones i d'homes que han tingut un pes important en l'evolució d’aquesta disciplina. Aquesta delica-

3 Conselleria de Benestar Social (1999). Las mujeres valencianas ante el siglo XXI. València: Generalitat Valenciana. 
Figura 3. Joc sobre igualtat de gènere en història de la química (interior).

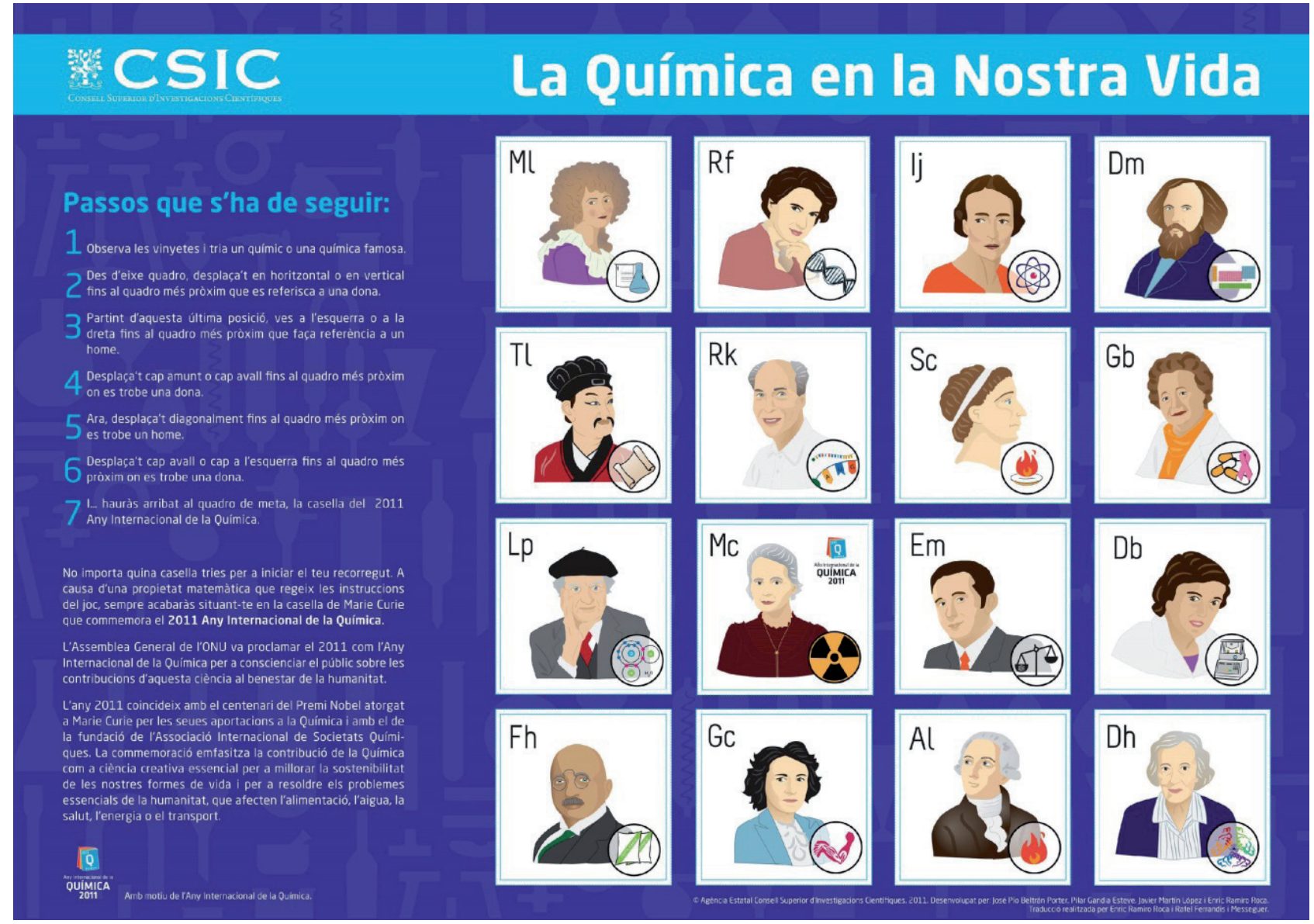

Font: elaboració pròpia.

da selecció de personatges històrics es va deixar en mans de l'esmentada institució que ens ho va proposar, ja que la concreció d'uns o altres no modificava el propòsit que ens havíem marcat i, a més, en garantia de forma qualitativa el bon repertori. Paral-lelament, es va estar treballant igualment a oferir una visió tan completa com fóra possible de la química sense prejudicis eurocèntrics, introduint figures erudites del món oriental, i es va marcar una cronologia clarament disciplinària amb un enllaç a l'etapa anterior dels alquimistes (vegeu figura 3 ).

En total, van ser setze noms els elegits, que es repartiren en quatre columnes de quatre fileres per conformar un quadrat. La distribució matemàtica de les seves imatges comportava que es triés visualment una figura $i$, mitjançant unes instruccions per moure sobre quadrat, tots acabaren per arribar a la cara per defecte: Maria
Skłodowska, més coneguda com Madame Curie (Salvat i Sánchez, 1992: 24-27).

La part visual es va realitzar amb dibuixos originals a partir de fotografies i representacions dels diferents científics, amb l'objectiu de donar-los un mateix tractament pictòric $i$ harmonia en la plasmació. A cada imatge s'hi van situar les inicials del seu nom i el logotip que representava la seua recerca. Igualment, es va acompanyar cada personatge amb una breu biografia (vegeu figura 4) sobre els fets més destacats que deixaren petjada en la història de la química.

D'aquesta manera, es va aconseguir disposar d'un joc commemoratiu de l'Any Internacional de la Química, on es donava una imatge igualitària de gènere de la seua evolució, que feia visible la importància de les dones a escala planetària i no tan sols occidental i que connectava també amb l'etapa alquimista. A més, es treballava el 
text instructiu, biogràfic i descriptiu, per oferir una gran diversitat de tipologies lingüístiques. $\mathrm{Si}$ a això hi sumem la part històrica i matemàtica del document i la lúdica de la seua execució, ens trobem amb un recurs complet, barat i atractiu, on l'entreteniment es barreja amb l'erudició i obre les portes a la comprensió per a qualsevol sector social.

En una primera etapa es va realitzar en format pòster i es va distribuir a tots els instituts del País Valencià, i posteriorment es va reproduir en A3 doblegat en forma de quadrat per a ús individual o grupal amb versions en castellà i valencià (vegeu figura 5). El producte final es va situar al web del CSIC (<http://www.dicv.csic.es/va/juegos.php $>$ ) i de forma gratuïta per a tots els particulars i institucions que ho van demanar, i així ampliava una mica més el concepte restrictiu de la seua divulgació inicial d'ús curricular i docent. Esperem que aquesta tendència continuï malgrat les dificultats econòmiques. Ara bé, el pas de la imatge -important, per descomptat-a un coneixement significatiu es va deixar en mans de mestres i professors, que són els professionals específics. El següent repte que plantegem és que aquesta informació i competència acadèmiques es transformin en alfabetització social, on collaboren els mitjans de comunicació i tots els altres sectors.

\section{Conclusions}

Hi ha hagut un avenç en la igualtat de gèneres si mirem d'una manera optimista com és el cas, però aquesta progressió no és suficient en la societat actual. S'ha detectat també una naturalització de la desigualtat i fins i tot una invisibilitat que cal denunciar, i potser un retrocés com a conseqüència de la crisi. Amb aquest panorama, és insubstituilble la tasca dels docents en les diverses etapes per formar generacions més

Figura 4. Joc sobre igualtat de gènere en història de la química (exterior).

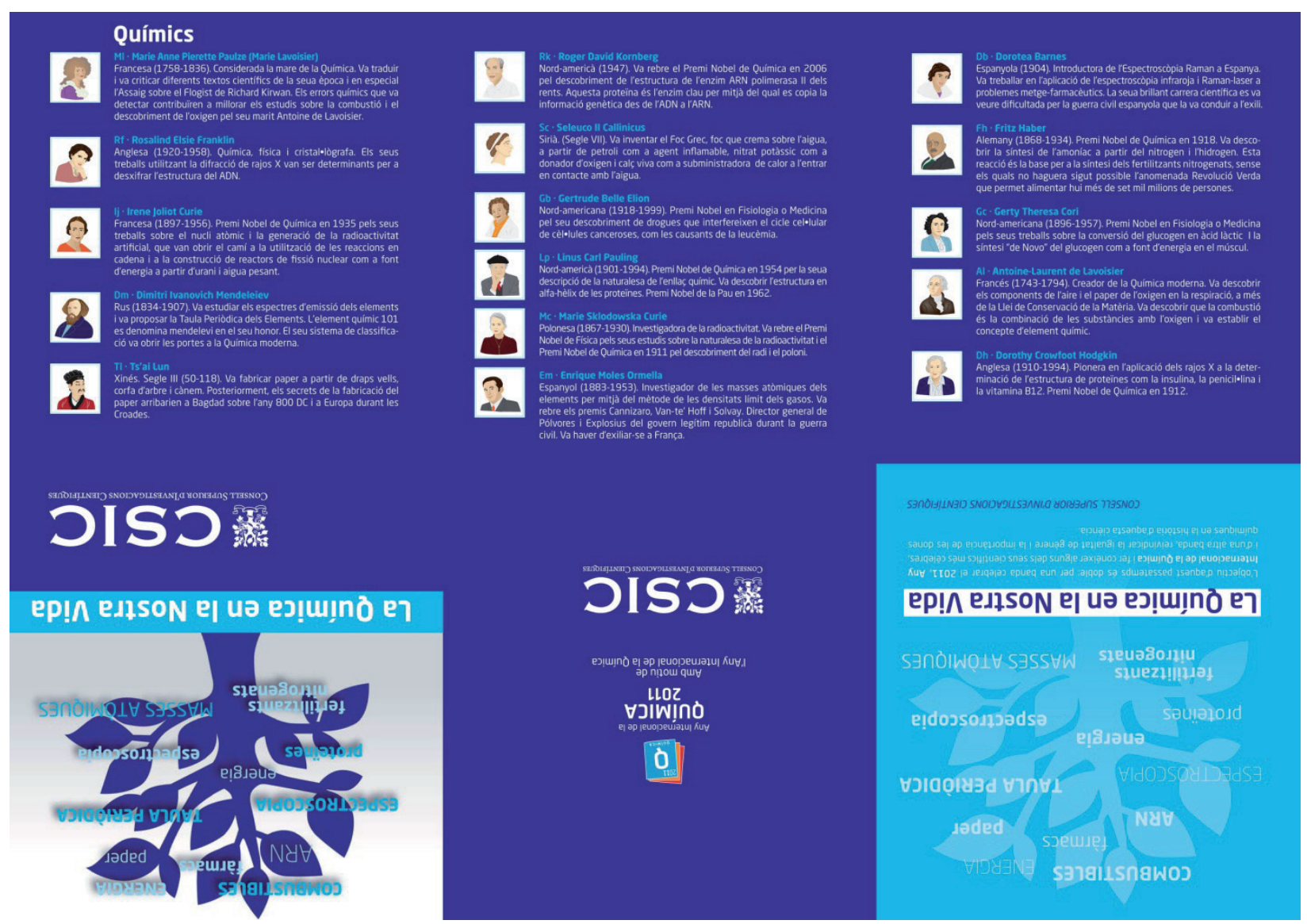

Font: elaboració pròpia. 
igualitàries en què compartir sigui natural amb independència del gènere. D'una banda, cal tenir en compte que el professorat no sempre és conscient de fins a quin extrem influeixen les seues creences pel que fa a gènere en la pràctica docent. D'altra banda, a l'escola encara hi perduren elements que reprodueixen i perpetuen prejudicis $i$ desigualtats referents a la cultura de gènere $i$ hi preval un règim de gènere que continua privilegiant el masculí, la qual cosa ens porta a la necessitat de revisar la situació dels currículums.

I com a possible concreció d'aquest treball necessari cap a la igualtat de gènere que encara està pendent, volem reivindicar la importància del joc com a recurs per aconseguir-la. Entenem que les activitats lúdiques tenen un important paper subliminal per crear llaços consistents entre lobjectiu proposat i la formació humana. Per a això, mostrem un testimoni concret que és compatible amb les tradicionals xerrades i activitats curriculars en general.

Esperem haver contribuiit amb aquest article a la reflexió necessària sobre la importància de fer visible el paper de la dona en la història de la química; de la necessitat de fer divulgació científica, i del valor del joc didàctic com a recurs transversal. Aquests tres elements -igualtat de gènere, alfabetització científica i renovació pedagògica- entenem que són responsabilitat de tota la societat i no tan sols dels docents.

Figura 5. Joc sobre igualtat de gènere en l'Any Internacional de la Química, del CSIC (plegat).

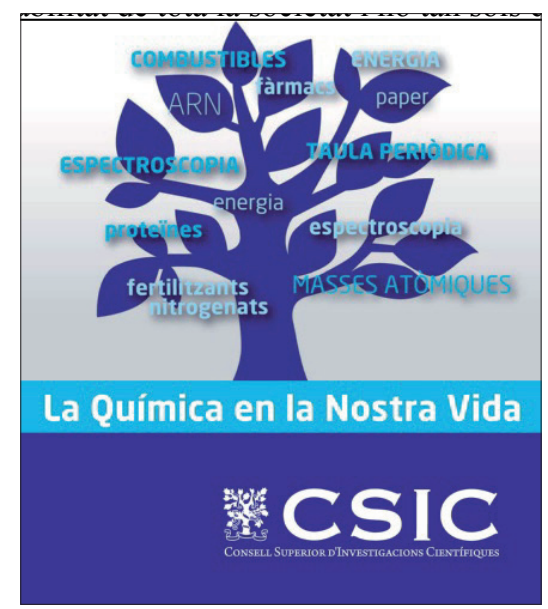

Font: elaboració pròpia.

\section{Bibliografia}

Ares Piquer, M. (2012). "La cultura de género en la cultura: actitudes del colectivo adolescente hacia la igualdad". Tendencias Pedagógicas, 19. Madrid: Universidad Autónoma.

Barnstonne, A.; Barnstone, W. (eds.) (1992). The book of women poets: from antiquity to now. Nova York: Shocken

Barragán, F.; González, J. (2007). "La construcción de la masculinidad en los contestos sociales". Revista de Investigación Educativa, 1, 25. Universidad de Murcia.

Connell, R. (1991). "The state, gender and sexual politics: theory and apparaissal", a: K. Davis; M. Leijensar; J. Oldersma (eds.). The gender of power. Londres: Sag.

CRAWFORD, M. (2006): Transformations. Women, gender and psychology. Boston: Mc-Graw Hill.

ElboJ, C.; Flecha, A.; İ̃̃Iguez, T. (2009). "Modelos de atracción y elección de la población adolescente y su relación con la violencia de género. Propuesta para su prevención en base a los principios metodológicos de las comunidades de aprendizaje". Contextos Educativos, 12. Logroño: Universidad de la Rioja.

García de Cortázar, M.; García de LeóN, M. A. (1997). "Mujeres en Minoría. Una investigación sociológica sobre las catedráticas de universidad en España”. Opiniones y Actitudes, 16. Madrid: CIS.

Martel, A. (1999). "Intervenciones educativas a favor de niñas y mujeres brillantes", a: ELLIS, J., et alii Niñas, mujeres y superdotación. Un desafío a la discriminación educativa en las mujeres. Madrid: Narcea.

Olmos Moreno, L. I. (2011). "La igualdad de oportunidades entre ambos sexos: técnicas para lograr un reto". Espiral. Cuadernos del Profesorado, 4 (8). Cuevas de Almanzora-Almería: CEP de Cuevas-Olula.

RAmiro RocA, E. (2004a). "Un gènere vingut a menys", a: Formación de la ciudadanía: las TICs y los nuevos problemas. Simposio Internacional de Didáctica de las Ciencias Sociales. Alacant: AGE.

- (2004b). Tòpics i adolescencia: una visió valenciana sobre les diferents autonomies. Castelló: Universitat Jaume I. 
Sabaté, A.; Rodríguez, J. M.; DíAz, M. Á. (1995). Mujeres, espacio y sociedad. Hacia una geografía del genero. Madrid: Síntesis.

Salvat, A.; Sánchez, J. (1992). "Els científics a l'escola primària". Comunicació Educativa 5. Tarragona: Universitat Rovira i Virgili. $<$ http://www.revistes.publicacionsurv.cat/ index.php/comeduc/article/view/179/173>. (Data de consulta: 03.08.2014). 